\title{
Aging Behaviour of Al-Mg-Si Alloys Subjected to Severe Plastic Deformation by ECAP and Cold Asymmetric Rolling
}

\author{
S. Farè, N. Lecis, and M. Vedani \\ Dipartimento di Meccanica, Politecnico di Milano, via Giuseppe La Masa, 1, 20156 Milan, Italy \\ Correspondence should be addressed to M. Vedani, maurizio.vedani@polimi.it
}

Received 22 March 2011; Accepted 12 June 2011

Academic Editor: Enrico Evangelista

Copyright () 2011 S. Farè et al. This is an open access article distributed under the Creative Commons Attribution License, which permits unrestricted use, distribution, and reproduction in any medium, provided the original work is properly cited.

A study was carried out on aging behaviour of a 6082 alloy processed by two different severe plastic deformation techniques: ECAP and asymmetric rolling. Both techniques were able to generate an ultrafine-grained structure in samples processed at room temperature. It was stated that severe straining promotes marked changes in the postdeformation aging kinetics. The peaks of $\beta^{\prime \prime} / \beta^{\prime}$ transition phases were anticipated and of progressively reduced intensity over the coarse grained alloy. A further peak accounting for onset of recrystallization also appeared in the most severely deformed samples. Full consistency in peak shape and position was found when comparing materials processed by ECAP and asymmetric rolling. Isothermal aging treatments performed at $180^{\circ} \mathrm{C}$ revealed that in the severely deformed samples, aging became so fast that the hardness curves continuously decreased due to overwhelming effects of structure restoration. On the contrary, aging at $130^{\circ} \mathrm{C}$ offers good opportunities for fully exploiting the precipitate hardening effects in the ultrafine-grained alloy.

\section{Introduction}

Wrought Al-Mg-Si alloys (6xxx series aluminum alloys) are widely used for structural applications in aerospace and automotive industries owing to their strength, formability, weldability, corrosion resistance, and cost. The age hardening response of 6xxx series alloys can be very significant, leading to remarkable improvement of strength after an appropriate heat treatment. Their precipitation sequence has been reported in numerous research works, and a satisfactory agreement on phase evolution occurring during aging has been achieved [1-7]. A large number of wrought Al-Mg-Si alloys contain an excess of $\mathrm{Si}$, above that required to form the $\mathrm{Mg}_{2} \mathrm{Si}(\beta)$ phase, to improve the age hardening response. For these alloys, the accepted precipitation sequence starting from a supersaturated solid solution is separate clusters of $\mathrm{Si}$ and $\mathrm{Mg}$ atoms, coclusters containing $\mathrm{Mg}$ and $\mathrm{Si}$ atoms, spherical GP zones, needle-like metastable $\beta^{\prime \prime}$ phase, rodlike metastable $\beta^{\prime}$ phase, Si precipitates, and platelets of equilibrium $\beta$ phase. Among these, the $\beta^{\prime \prime}$ precipitates are considered to give the main contribution to strength and hence they are mostly responsible for the peak age hardening effect $[2,4,5,8]$.
Several research works showed that the precipitation kinetics and even precipitation sequence are changed when the alloy structure is plastically deformed. Zhen et al. [5, 9] showed that when Al-Mg-Si alloys had been extensively cold rolled, their aging curves featured a decrease of the precipitation temperatures of some phases. It was suggested that the increased density of defects in the crystal structure would enhance appreciably the diffusion distance of $\mathrm{Si}$ and hence promote the formation of a more obvious peak for the GP zones, the anticipation of the metastable $\beta^{\prime \prime} / \beta^{\prime}$ peak temperatures, and the reduction of the amount of $\mathrm{Si}$ and $\mathrm{Mg}_{2}$ Si phases that eventually formed.

Similar modifications in the precipitation sequence were also found in alloys deformed in the severe plastic deformation (SPD) regime, to produce ultrafine-grained alloys. Murayama et al. [10] investigated a solution treated $\mathrm{Al}-\mathrm{Cu}$ binary alloy processed by equal channel angular pressing (ECAP) to refine its structure at room temperature. By careful DSC and TEM analyses, they stated that during postECAP aging, the formation of GP zones and of transition $\theta^{\prime \prime}$ precipitates was suppressed and that the precipitation of $\theta^{\prime}$ and $\theta\left(\mathrm{Al}_{2} \mathrm{Cu}\right)$ phases was enhanced and occurred at lower temperatures in the heavily deformed structure of 
TABLE 1: Chemical composition (mass \%) of the 6082 alloy investigated.

\begin{tabular}{lccccccc}
\hline $\mathrm{Mg}$ & $\mathrm{Si}$ & $\mathrm{Mn}$ & $\mathrm{Fe}$ & $\mathrm{Cu}$ & $\mathrm{Cr}$ & $\mathrm{Ti}$ & $\mathrm{Al}$ \\
\hline 1.193 & 1.019 & 0.650 & 0.267 & 0.005 & 0.010 & 0.015 & balance \\
\hline
\end{tabular}

the alloys. Huang and coworkers [11] consistently stated that in a laboratory $\mathrm{Al}-4 \mathrm{wt} . \% \mathrm{Cu}$ alloy severely deformed after solution annealing, copious precipitation of $\theta$ phase occurred at grain boundaries on natural aging, while no indication of $\theta^{\prime \prime}, \theta^{\prime}$, or GP zones formation was observed. Gubicza et al. [12] obtained similar conclusions on supersaturated $\mathrm{Al}-\mathrm{Zn}-\mathrm{Mg}$ alloys processed by ECAP at $200^{\circ} \mathrm{C}$. They observed that high-temperature straining suppresses the formation of GP zones and $\eta^{\prime}$ transition precipitates while enhancing the precipitation kinetics of the $\eta$ precipitates over the conventionally solution treated and artificially aged alloys.

Information on aging response of SPD-processed 6xxx alloys is also available. Roven and coauthors [8] investigated the precipitation behaviour of a 6063 alloy during ECAP at $\mathrm{RT}$ and at $175^{\circ} \mathrm{C}$ and found that spherical $\beta^{\prime \prime}$ precipitates are dynamically formed from the as-solutionized alloy during SPD even at RT, instead of the needle-like $\beta^{\prime \prime}$ transition precipitates that are usually observed in conventionally aged alloys. Some of the present authors $[13,14]$ investigated the aging behaviour of several wrought alloys of the $\mathrm{Al}-\mathrm{Mg}-\mathrm{Si}$ system after ECAP and showed that precipitation kinetics in the ultrafine-grained alloys was markedly accelerated over the coarse-grained materials. It was also demonstrated that the formation of $\beta^{\prime \prime} / \beta^{\prime}$ phases occurred at lower temperatures with increasing ECAP strain, whereas $\beta^{\prime}$ precipitation was strongly reduced due to expected formation of competing Si-rich phases in the heavily deformed structure.

In the present paper, comparative results are presented on post-SPD aging behaviour of a commercial $6082 \mathrm{Al}$ alloy severely deformed at room temperature by two different techniques. Available data on ECAP processed alloys in the as-solution annealed condition are compared to results obtained on the same materials deformed by asymmetric rolling. Investigations on aging kinetics and structure development allowed to draw conclusions on aging behaviour aimed at defining optimal parameters and treatment feasibility for ultrafine-grained Al-Mg-Si alloys.

\section{Materials and Experimental Procedures}

A commercial $6082 \mathrm{Al}$ alloy supplied in the form of extruded bars was investigated. The alloy chemical composition is given in Table 1.

For ECAP processing, samples having a length of $100 \mathrm{~mm}$ and a diameter of $10 \mathrm{~mm}$ were cut from the bars, solution treated in a muffle furnace at $530^{\circ} \mathrm{C}$ for 2 hours and water quenched.

ECAP pressing was carried out using a die with channels intersecting at an angle $\Phi$ of $90^{\circ}$ and with an external curvature angle $\Psi$ of $20^{\circ}$, corresponding to a theoretical strain of 1.05 for each pass [15]. Samples were processed at room temperature by the so-called route $\mathrm{C}$ (rotation by $180^{\circ}$ of the specimen at each pass) to accumulate up to six passes. The experimental details of the ECAP facility and material processing are described elsewhere [16].

For asymmetric rolling (ASR) in the SPD regime, samples having a thickness of $20 \mathrm{~mm}$ and width of $40 \mathrm{~mm}$ were cut and subjected to the same solution treatment above mentioned. Cold rolling reduction was performed down to a thickness of $0,23 \mathrm{~mm}$ by a multipass procedure with no intermediate annealing treatments. The rolling schedule consisted of thickness reductions of about $20 \%$ at each step and the rotation of the billet along its longitudinal axis before each pass (a procedure equivalent to route $\mathrm{C}$ adopted for ECAP). The asymmetry ratio, namely, the rotational speed ratio between the two rolls, was set to 1,4 on the basis of previous studies [17]. A laboratory rolling mill in a twohigh configuration, featuring the possibility of independently modifying the rotational speed of the rolls, was adopted for this purpose.

Analyses on grain structure evolution and on precipitates developed in SPD processed and aged samples was performed by TEM. Disk samples were prepared by cutting disks from ECAP billets and rolled samples, manually grinding and polishing. Twin jet electrolytic thinning was then carried out at $-35^{\circ} \mathrm{C}$ with a $30 \% \mathrm{HNO}_{3}$ solution in methanol at $18 \mathrm{~V}$.

Samples of the processed alloy were subjected to DSC analyses to investigate the influence of SPD on precipitation kinetics. Runs were carried out on samples having a weight of about $50 \mathrm{mg}$ in a purified argon atmosphere with a scanning rate of $20^{\circ} \mathrm{C} / \mathrm{min}$. The effects associated to transformation reactions were isolated by subtracting a baseline recorded form high-purity Al runs.

Vickers microhardness adopting a load on the indenter of $1 \mathrm{~N}$ was adopted to evaluate modification of alloy strength. Evolution of microhardness was assessed as a function of aging time during isothermal treatments at temperatures of 180 and $130^{\circ} \mathrm{C}$. The profiles allowed to state the peakhardness aging times of the processed alloy as a function of the strain imparted either by ECAP or by ASR. Comparative results are presented in this paper considering the equivalent strain experienced. For ECAP, the Iwahashi equivalent strain was calculated [15] whereas for ASR, the equivalent Von Mises strain was evaluated, assuming plane strain deformation [18], by

$$
\varepsilon_{\mathrm{eq}}=\frac{2}{\sqrt{ } 3} \cdot \ln \left(\frac{h_{0}}{h_{f}}\right) \cdot \varnothing
$$

with $h_{0}$ and $h_{f}$ being the initial and final thickness, respectively, and $\varnothing$ a parameter accounting for the asymmetry effects. 


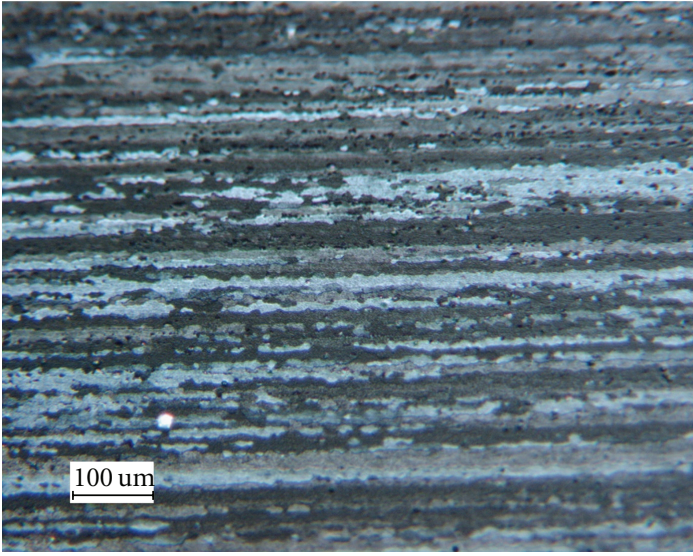

(a)

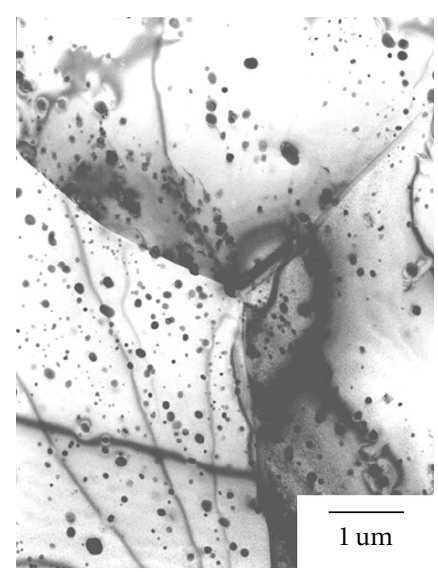

(b)

FIGURE 1: Microstructure of the coarse grained $6082 \mathrm{Al}$ alloy before SPD. (a) Optical and (b) TEM micrographs.

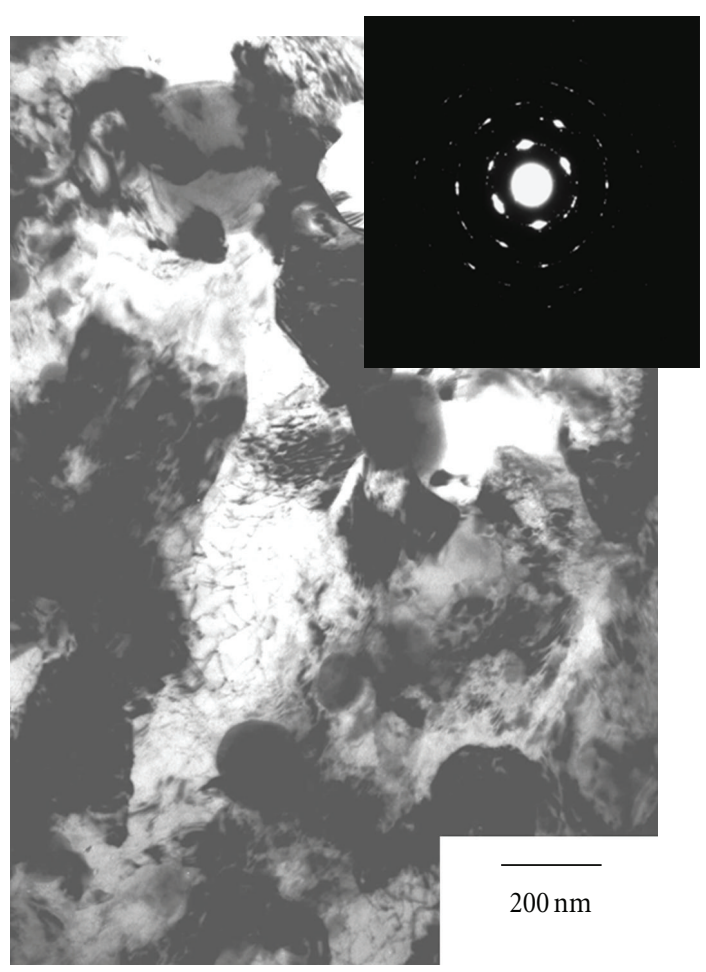

(a)

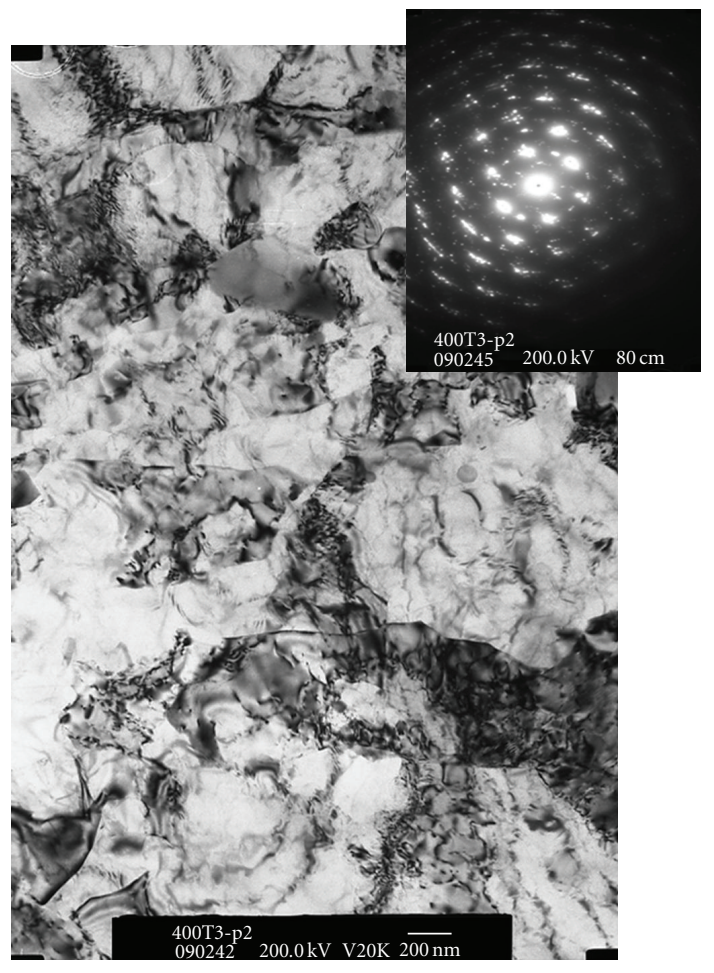

(b)

FIGURE 2: Representative TEM images and corresponding SAD patterns of the ultrafine structure achieved after (a) 6 ECAP passes and (b) asymmetric rolling reduction corresponding to 5,50 equivalent strain.

\section{Results and Discussion}

3.1. Grain Structure after SPD. In Figures 1 and 2, sets of representative micrographs showing the initial solution annealed coarse structure and its evolution toward the ultrafine scale by ECAP and ASR are reported. Details of the microstructure evolution during ECAP and ASR processing have already been published elsewhere $[13,17]$. It is worth considering here that for both processes, after the first passes, sets of parallel bands of subgrains a few hundreds of micrometers in width are formed. By increasing the number of passes, the subboundary misalignment increased (as inferred by the increased spreading of the spots of the SAD patterns). Eventually, subgrain fragmentation and further increase of the misalignment led to an ultrafine equiaxed high-angle grain structure. For both processes, the average grain size achieved after the highest imparted strain (6 ECAP passes corresponding to an equivalent strain of 6,33 and 


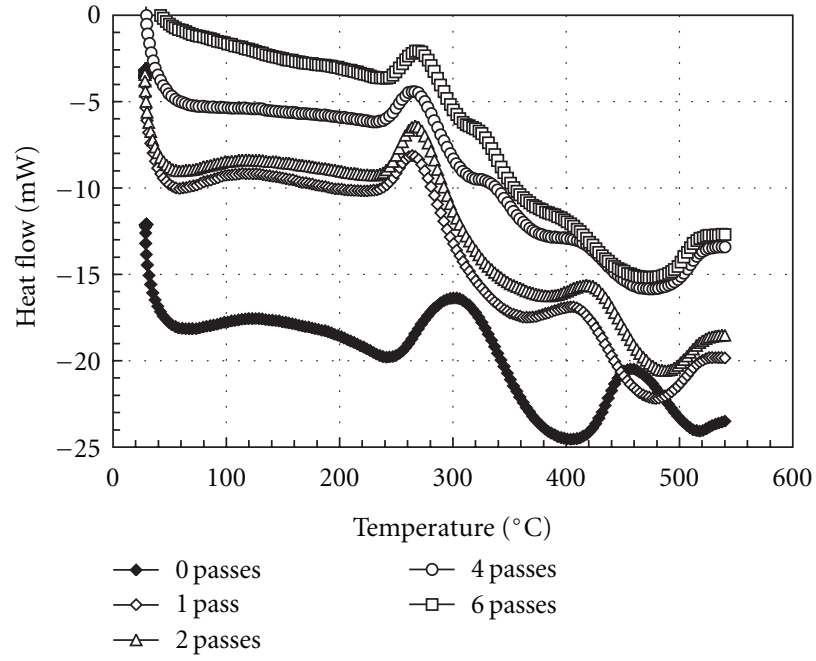

(a)

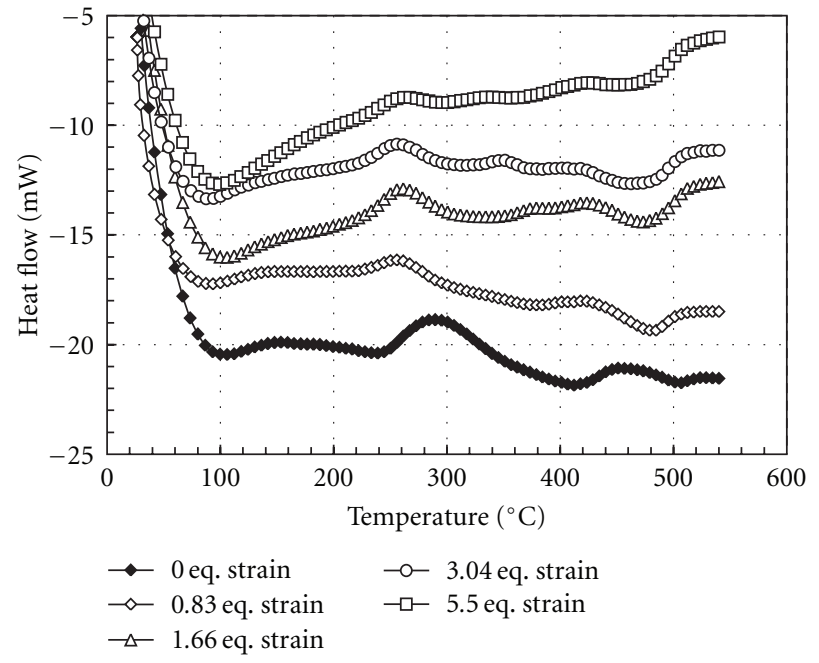

(b)

FIGURE 3: DSC curves of the solution annealed and SPD processed 6082 alloy as a function of (a) ECAP passes and (b) amount of equivalent strain imparted by ASR. The curves are arbitrarily shifted along $y$-axis to avoid superposition.

reduction down to a thickness of $0,23 \mathrm{~mm}$, corresponding to an equivalent strain of 5,50 for asymmetric rolling) was of about $300 \mathrm{~nm}$.

\subsection{Differential Scanning Calorimetry. Figure 3 summarizes} typical DSC runs recorded as a function of ECAP passes and equivalent strain given by ASR of the solution-treated 6082 alloy. The thermograms of the unprocessed solution treated alloy match the established aging sequence of this alloy [13 , 9]. In particular, the broad exothermic peak (upward peak) in the plot of Figure $3(\mathrm{a})$ at $305^{\circ} \mathrm{C}$, often interpreted as two partially superimposed subpeaks, corresponds to the formation of $\beta^{\prime \prime}$ and $\beta^{\prime}$ metastable precipitates at about $270^{\circ} \mathrm{C}$ and $330^{\circ} \mathrm{C}$, respectively. More specifically, it was suggested that the subpeak at $270^{\circ} \mathrm{C}$ could also be related to precipitation of tiny Si-rich particles acting as precursors for the formation of the $\beta^{\prime \prime}$ phase and that the peak at $330^{\circ} \mathrm{C}$ corresponds to formation of both rod-shaped $\beta^{\prime}$ phase and relatively large Si-rich precipitates $[1,2,9]$. A dissolution endothermic trough (downward peak in the plot) of the above phases follows at about $400^{\circ} \mathrm{C}$, while the second marked exothermic peak at $460^{\circ} \mathrm{C}$ and the corresponding endothermic trough at $520^{\circ} \mathrm{C}$ are related to the formation and dissolution of the equilibrium $\beta-\mathrm{Mg}_{2}$ Si phase.

The ECAP processed alloys (see Figure 3(a)) feature marked differences in position and shape of the peaks. The above described broad peak related to the formation of $\beta^{\prime \prime}$ and $\beta^{\prime}$ phases now appears as a more narrow peak centred at $275^{\circ} \mathrm{C}$, irrespective of the number of ECAP passes experienced. The formation of the stable $\beta$ precipitates in the severely deformed alloy revealed to be markedly anticipated $\left(405-415^{\circ} \mathrm{C}\right)$ and of progressively reduced intensity with respect to the unprocessed solution treated alloy. It is also worth noting that a new peak appears at about $330^{\circ} \mathrm{C}$ in the alloy processed to 4 and 6 ECAP passes and in ASR samples deformed to similar equivalent strains (see arrows in Figures 3(a) and 3(b)). In a previous study, some of the present authors focussed on the interpretation of aging peaks of ECAP processed Al-Mg-Si alloys of similar composition [14]. By TEM analysis of samples aged in the DSC just immediately before the onset, and after the offset of this peak, they were able to demonstrate that this unexpected hump detected in the most strain-hardened samples was related to recrystallization phenomena that became more evident and developed at decreasing temperatures as ECAP strain increased.

Finally, comparison between Figures 3(a) and 3(b) supplies evidence about similarities of effects promoted by ECAP and ASR processes. Inspection of the thermograms reveals full consistency of peak positions as a function of strain (it is to remind that each ECAP pass corresponds to a strain of 1,05$)$ for the two SPD techniques here considered. The only difference concerns the amplitude of precipitate peaks that is supposed to be due to different weight of samples. Indeed, due to geometrical constraints, the samples cut from the ASR thin sheets had a less regular shape with a higher surface/volume ratio.

While information on ECAP effects on aging was already available in the literature owing to a number of published research studies $[8,10-12,19]$, data on aging behaviour in $\mathrm{Al}$ alloys severely deformed by cold rolling are relatively less frequent. The present data on aging of ASR performed in the severe deformation regime (up to 5,50 equivalent strain) are indeed in good agreement with established evidence showing that kinetics and morphology of transition precipitates are deeply altered by SPD and that new opportunities for isothermal aging at lower temperatures deserve to be explored owing to accelerated diffusion of alloying elements in the heavily dislocated alloy structure. It is worth mentioning that studies were carried recently on 6061 and $6063 \mathrm{Al}$ alloys subjected to room temperature and cryogenic rolling in the severe plastic deformation regime $[20,21]$. 


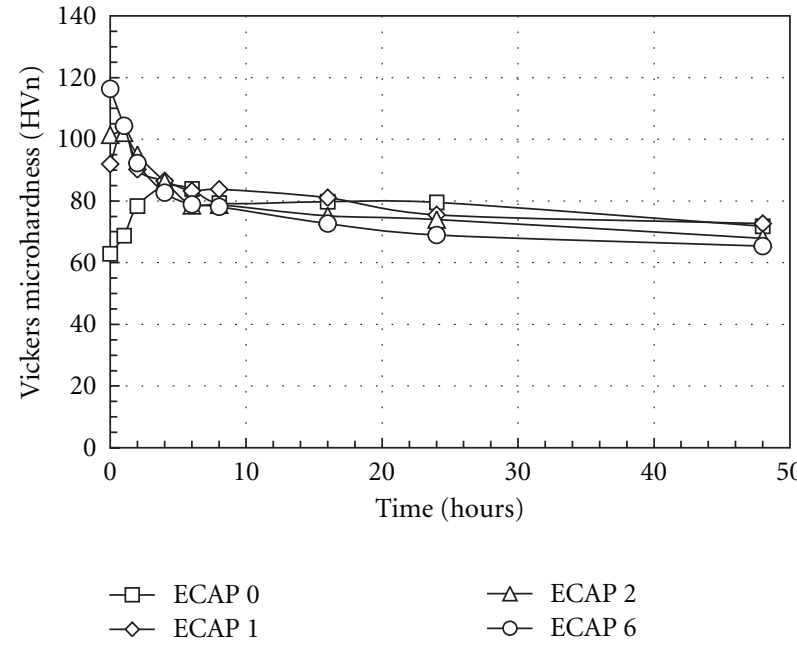

(a)
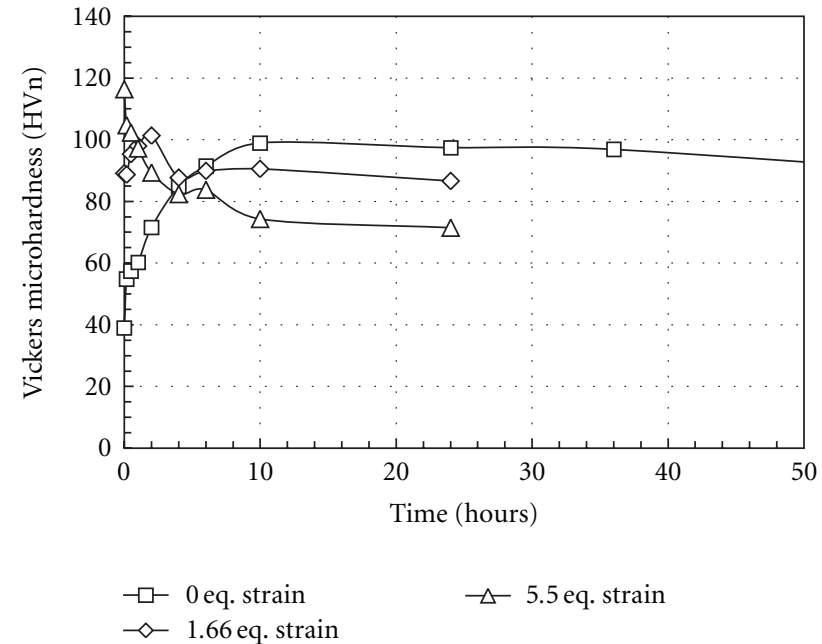

(b)

FIGURE 4: Aging curves at $180^{\circ} \mathrm{C}$ of the solution annealed and SPD processed 6082 alloy as a function of (a) ECAP passes and (b) amount of equivalent strain imparted by ASR.

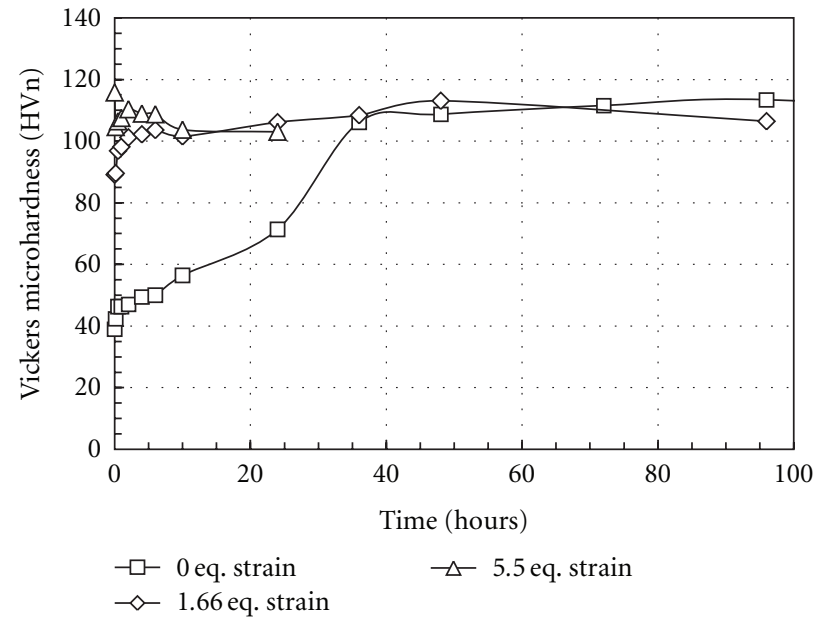

(a)

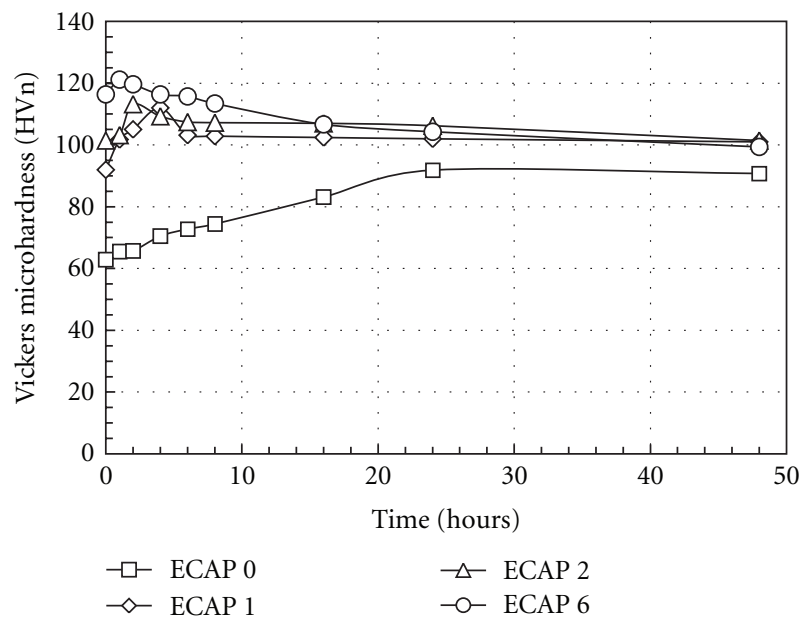

(b)

FIGURE 5: Aging curves at $130^{\circ} \mathrm{C}$ of the solution annealed and SPD processed 6082 alloy as a function of (a) ECAP passes and (b) amount of equivalent strain imparted by ASR.

It was observed that low-temperature processing causes substantial suppression of structure recovery during straining and hence preserves higher dislocation densities in the samples, increasing the driving force for sub-microcrystalline grain development. This feature was more significant when presolution annealed alloys were processed due to effects of solute elements (mainly Mg and Si for 6xxx series alloys) in pinning dislocations and retarding their annihilation during deformation.

A further issue related to aging of UFG structures was considered by Chinh and coauthors [22] who proposed several strategies for processing age-hardenable alloys. It was stated that for Al-Mg-Zn-Zr alloys, ECAP processing should be performed immediately after quenching or at least within a very short period of preaging, to avoid excessive strengthening effects related to anticipated aging and hence formation of cracks during further ECAP passes.

3.3. Aging Kinetics. Post-SPD aging behaviour was further investigated by isothermal treatments at 130 and $180^{\circ} \mathrm{C}$. The evolution of microhardness as a function of aging time at the above-mentioned temperatures is depicted in Figures 4 and 5 .

When comparing the peak-hardness times as a function of the amount of strain experienced by the alloy prior to the aging treatment, it is readily confirmed that severe plastic deformation remarkably accelerates the aging kinetics, consistently with previous DSC results. For the alloy processed to the highest strain levels (e.g., 6 passes by ECAP and 5,50 equivalent strain by ASR), aging at $180^{\circ} \mathrm{C}$ became so fast 


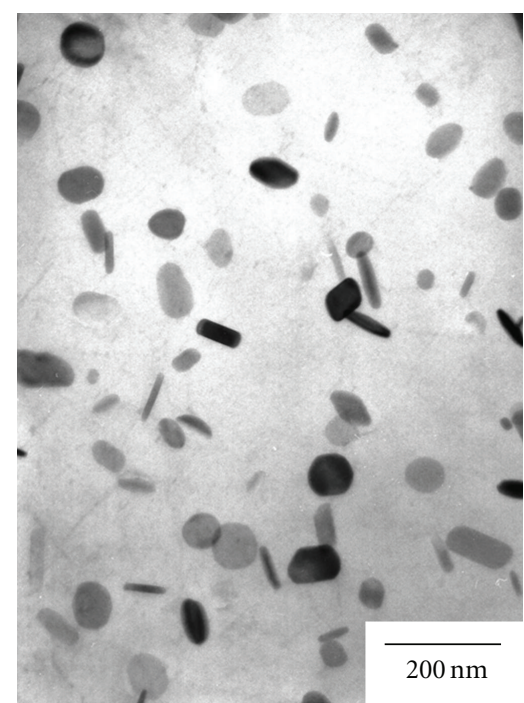

(a)

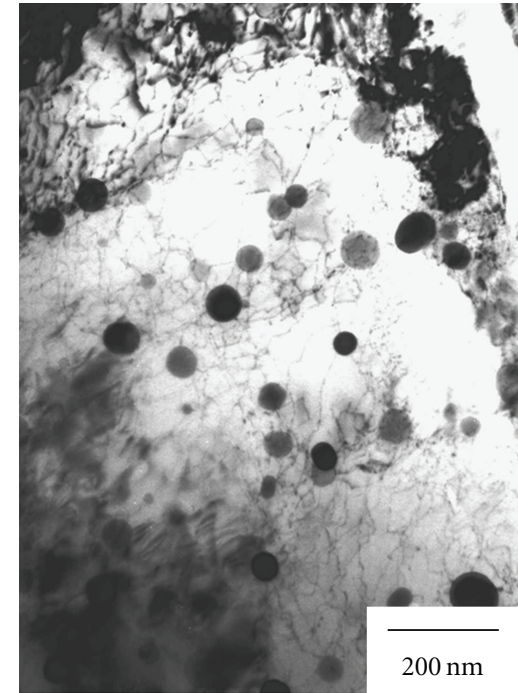

(b)

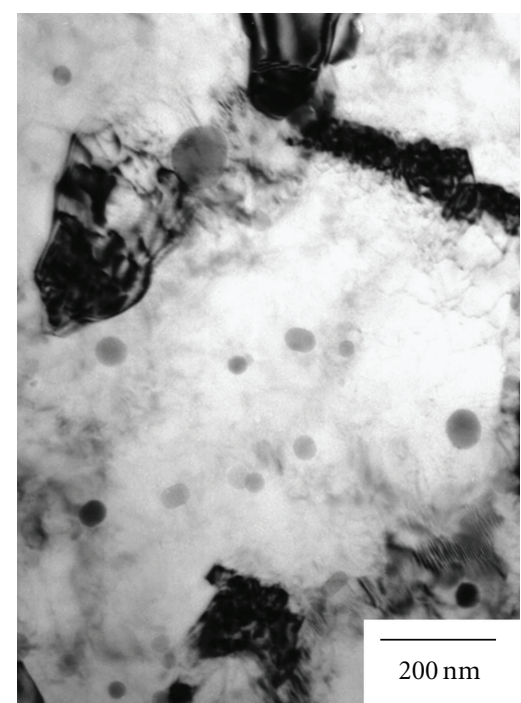

(c)

FIGURE 6: Morphology of strengthening precipitates detected in (a) solution annealed and peak aged coarse-grained alloy, (b) presolution annealed and peak-aged after 1 ECAP pass, (c) presolution annealed and peak-aged after 6 ECAP passes [13].

that the hardness curves continuously decreased, starting from beginning of the aging treatment (see Figure 4). It must be considered that during aging, recovery of the heavily deformed structure and precipitation from the supersaturated solution can simultaneously occur. The former mechanism lowers defect density, which results in decreasing strength, the latter contributes to increased density of dispersoids and hence improves the strengthening effect. The continuous loss of hardness detected during aging at $180^{\circ} \mathrm{C}$ here reported is therefore supposed to be due to overwhelming restoration mechanisms of the deformed structure over the precipitation hardening potential, in good accordance with other literature reports [19]. The data shown in Figure 5 suggests that isothermal aging carried out at $130^{\circ} \mathrm{C}$ on presolutionised and SPD processed alloys could supply interesting opportunities for fully exploiting the precipitate hardening effects while controlling the stored energy in the structure. This evidence is confirmed by investigations carried out by Panigrahi et al. [21] and by Niranjani et al. [23] showing that even temperatures as low as $100^{\circ} \mathrm{C}$ can be successfully selected for aging of $\mathrm{Al}-\mathrm{Mg}-\mathrm{Si}$ alloys after severe plastic deformation by rolling. Nikitina et al. [24] considered an $\mathrm{Al}-\mathrm{Cu}-\mathrm{Mg}-\mathrm{Si}$ alloy processed by HPT and investigated structural stability and aging behaviour of the UFG alloy. Also these authors found evidence of a markedly anticipated aging behaviour by DSC and highlighted by microhardness measurements that the SPD processed samples underwent significant softening during treatments at temperatures exceeding $175^{\circ} \mathrm{C}$ even for aging times as low as 30 minutes.

From present data, it can be suggested that a proper combination of grain-refinement strengthening and agehardening can be fully exploited in solution annealed UFG alloys only when isothermal aging is performed at temperatures significantly lower than conventional values and for shorter periods that have to be tailored to specific amount of strain imparted during SPD and alloy composition. Stability of UFG structure would also be preserved by the addition of dispersoid-forming elements that could retard restoration during aging [14].

3.4. Strengthening Precipitates. Investigation on the strengthening precipitate structure found in the SPD processed samples was carried out only on a limited number of ECAP conditions [13]. Figure 6 depicts a colletion of TEM micrographs taken from ECAP samples peak aged at $130^{\circ} \mathrm{C}$. The peak aging time of each condition was selected on the basis of the hardness curves previously reported in Figure 5(a). The solution annealed and peak aged 6082 alloy (undeformed sample) featured a dispersion of about $0,1 \mu \mathrm{m}$ long rod-like phases identified as $\beta^{\prime}$ precipitates on the basis of their morphology $[1,2]$ together with globular particles with an average size of $50 \mathrm{~nm}$. In the ECAP processed samples shown in Figures 6(b) and 6(c), arrangement of dislocation in the matrix was observed according to expected recovery mechanisms acting during aging. Moreover, the above-mentioned globular particles became predominant over the rod-like precipitates.

\section{Conclusions}

A study was carried out on aging of a 6082 alloy processed by two different severe plastic deformation techniques. From comparative analysis of the results, the following conclusions can be drawn.

(i) Both ECAP and ASR were able to generate an ultrafine structure consisting of equiaxed grains after extensive deformation at room temperature. At the highest strain investigated, of 6 ECAP passes (corresponding to an equivalent strain of 6,33) and of an equivalent strain of 5,50 given by ASR, an average grain size of about $300 \mathrm{~nm}$ was detected. 
(ii) DSC analyses revealed that SPD carried out on the presolution annealed alloy promotes marked changes in the postdeformation aging kinetics. The peaks of $\beta^{\prime \prime} / \beta^{\prime}$ transition phases were anticipated and of progressively reduced intensity over the conventional coarse grained (not processed by SPD) alloy. A peak accounting for onset of recrystallization also appeared in samples deformed for more than 4 passes by ECAP or rolled by ASR at equivalent strains exceeding 3. A full consistency in peak shape and position was found when comparing materials processed by the two SPD techniques and strained at comparable levels.

(iii) Isothermal aging treatments performed at 130 and $180^{\circ} \mathrm{C}$ on the presolution annealed and SPD processed samples were considered to establish optimal aging times and to evaluate the achievable strength by microhardness. It was confirmed that SPD remarkably accelerates the aging kinetics. For the alloy processed to the highest strain levels, aging at $180^{\circ} \mathrm{C}$ became so fast that the hardness curves continuously decreased due to overwhelming effects of structure restoration. On the contrary, aging carried out at $130^{\circ} \mathrm{C}$ offered good opportunities for fully exploiting the precipitate hardening effects, while preserving the ultrafine-grained structure.

(iv) TEM investigations performed on selected samples aged at $130^{\circ} \mathrm{C}$ to peak hardness condition showed that the rod-like $\beta^{\prime}$ transition phase typically found in the coarse grained samples was progressively replaced by globular precipitates in ultrafine SPD processed samples.

(v) The experimental data here presented suggest that a proper combination of grain-refinement strengthening and age-hardening can be fully exploited in solution annealed UFG alloys only when isothermal aging is performed at temperatures significantly lower than conventional values and for shorter periods. Aging conditions have to be tailored to specific amount of strain imparted during SPD and to alloy composition.

\section{Acknowledgments}

The authors would like to thank Dr. G. Angella for TEM analyses. This research was partially financed by MIUR within the framework of PRIN projects under Grant 2008YNZB7M.

\section{References}

[1] K. Gupta, D. J. Lloyd, and S. A. Court, "Precipitation hardening in Al-Mg-Si alloys with and without excess Si," Materials Science and Engineering A, vol. 316, no. 1-2, pp. 11$17,2001$.

[2] G. A. Edwards, K. Stiller, G. L. Dunlop, and M. J. Couper, "The precipitation sequence in Al-Mg-Si alloys," Acta Materialia, vol. 46, no. 11, pp. 3893-3904, 1998.
[3] K. Matsuda, Y. Sakaguchi, Y. Miyata et al., "Precipitation sequence of various kinds of metastable phases in Al1.0mass\% Mg2Si-0.4mass\% Si alloy," Journal of Materials Science, vol. 35, no. 1, pp. 179-189, 2000.

[4] M. Takeda, F. Ohkubo, T. Shirai, and K. Fukui, "Stability of metastable phases and microstructures in the ageing process of Al-Mg-Si ternary alloys," Journal of Materials Science, vol. 33, no. 9, pp. 2385-2390, 1998.

[5] L. Zhen, W. D. Fei, S. B. Kang, and H. W. Kim, "Precipitation behaviour of Al-Mg-Si alloys with high silicon content," Journal of Materials Science, vol. 32, no. 7, pp. 1895-1902, 1997.

[6] M. Murayama and K. Hono, "Pre-precipitate clusters and precipitation processes in Al-Mg-Si alloys," Acta Materialia, vol. 47, no. 5, pp. 1537-1548, 1999.

[7] G. Biroli, G. Caglioti, L. Martini, and G. Riontino, "Precipitation kinetics of AA4032 and AA6082: a comparison based on DSC and TEM," Scripta Materialia, vol. 39, no. 2, pp. 197-203, 1998.

[8] H. J. Roven, M. Liu, and J. C. Werenskiold, "Dynamic precipitation during severe plastic deformation of an Al-Mg-Si aluminium alloy," Materials Science and Engineering A, vol. 483-484, no. 1-2 C, pp. 54-58, 2008.

[9] S. B. Kang, L. Zhen, H. W. Kim, and S. T. Lee, "Effect of cold rolling and aging treatment on mechanical property and precipitation behavior in a Al-Mg-Si alloy," Materials Science Forum, vol. 217-222, no. 2, pp. 827-832, 1996.

[10] M. Murayama, Z. Horita, and K. Hono, "Microstructure of two-phase Al-1.7 at\% Cu alloy deformed by equal-channel angular pressing," Acta Materialia, vol. 49, no. 1, pp. 21-29, 2001.

[11] Y. Huang, J. D. Robson, and P. B. Prangnell, "The formation of nanograin structures and accelerated room-temperature theta precipitation in a severely deformed $\mathrm{Al}-4 \mathrm{wt} . \% \mathrm{Cu}$ alloy," Acta Materialia, vol. 58, no. 5, pp. 1643-1657, 2010.

[12] J. Gubicza, I. Schiller, N. Q. Chinh, J. Illy, Z. Horita, and T. G. Langdon, "The effect of severe plastic deformation on precipitation in supersaturated Al-Zn-Mg alloys," Materials Science and Engineering A, vol. 460-461, pp. 77-85, 2007.

[13] G. Angella, P. Bassani, A. Tuissi, and M. Vedani, "Aging behaviour and mechanical properties of a solution treated and ECAP processed 6082 alloy," Materials Transactions, vol. 45, no. 7, pp. 2282-2287, 2004.

[14] M. Vedani, G. Angella, P. Bassani, D. Ripamonti, and A. Tuissi, "DSC analysis of strengthening precipitates in ultrafine AlMg-Si alloys," Journal of Thermal Analysis and Calorimetry, vol. 87, no. 1, pp. 277-284, 2007.

[15] Y. Iwahashi, J. Wang, Z. Horita, M. Nemoto, and T. G. Langdon, "Principle of equal-channel angular pressing for the processing of ultra-fine grained materials," Scripta Materialia, vol. 35, no. 2, pp. 143-146, 1996.

[16] M. Vedani, P. Bassani, M. Cabibbo, and E. Evangelista, "Experimental aspects related to equal channel angular pressing of a commercial AA6082 alloy," Metallurgical Science and Technology, vol. 21, p. 3, 2003.

[17] S. Farè, M. Vedani, and G. Angella, "Features on grainstructure evolution during asymmetric rolling of aluminium alloys," Materials Science Forum, vol. 604-605, pp. 77-85, 2009.

[18] Q. Cui and K. Ohori, "Grain refinement of high purity aluminium by asymmetric rolling," Materials Science and Technology, vol. 16, no. 10, pp. 1095-1101, 2000.

[19] E. Cerri and P. Leo, "Influence of severe plastic deformation on aging of Al-Mg-Si alloys," Materials Science and Engineering A, vol. 410-411, pp. 226-229, 2005. 
[20] W. J. Kim, J. Y. Wang, S. O. Choi, H. J. Choi, and H. T. Sohn, "Synthesis of ultra high strength Al-Mg-Si alloy sheets by differential speed rolling," Materials Science and Engineering A, vol. 520, no. 1-2, pp. 23-28, 2009.

[21] S. K. Panigrahi, R. Jayaganthan, and V. Pancholi, "Effect of plastic deformation conditions on microstructural characteristics and mechanical properties of Al 6063 alloy," Materials and Design, vol. 30, no. 6, pp. 1894-1901, 2009.

[22] N. Q. Chinh, J. Gubicza, T. Czeppe et al., "Developing a strategy for the processing of age-hardenable alloys by ECAP at room temperature," Materials Science and Engineering A, vol. 516, no. 1-2, pp. 248-252, 2009.

[23] V. L. Niranjani, K. C. Hari Kumar, and S. Subramanja Sarma, "Development of high strength Al-Mg-Si AA6061 alloy through cold rolling and ageing," Materials Science and Engineering A, vol. 515, no. 1-2, pp. 169-174, 2009.

[24] M. A. Nikitina, R. K. Islamgaliev, and A. F. Kamalov, “Thermal stability of the ultrafine-grained $\mathrm{Al}-\mathrm{Cu}-\mathrm{Mg}-\mathrm{Si}$ aluminum alloy," Reviews on Advanced Materials Science, vol. 25, no. 1, pp. 74-81, 2010. 

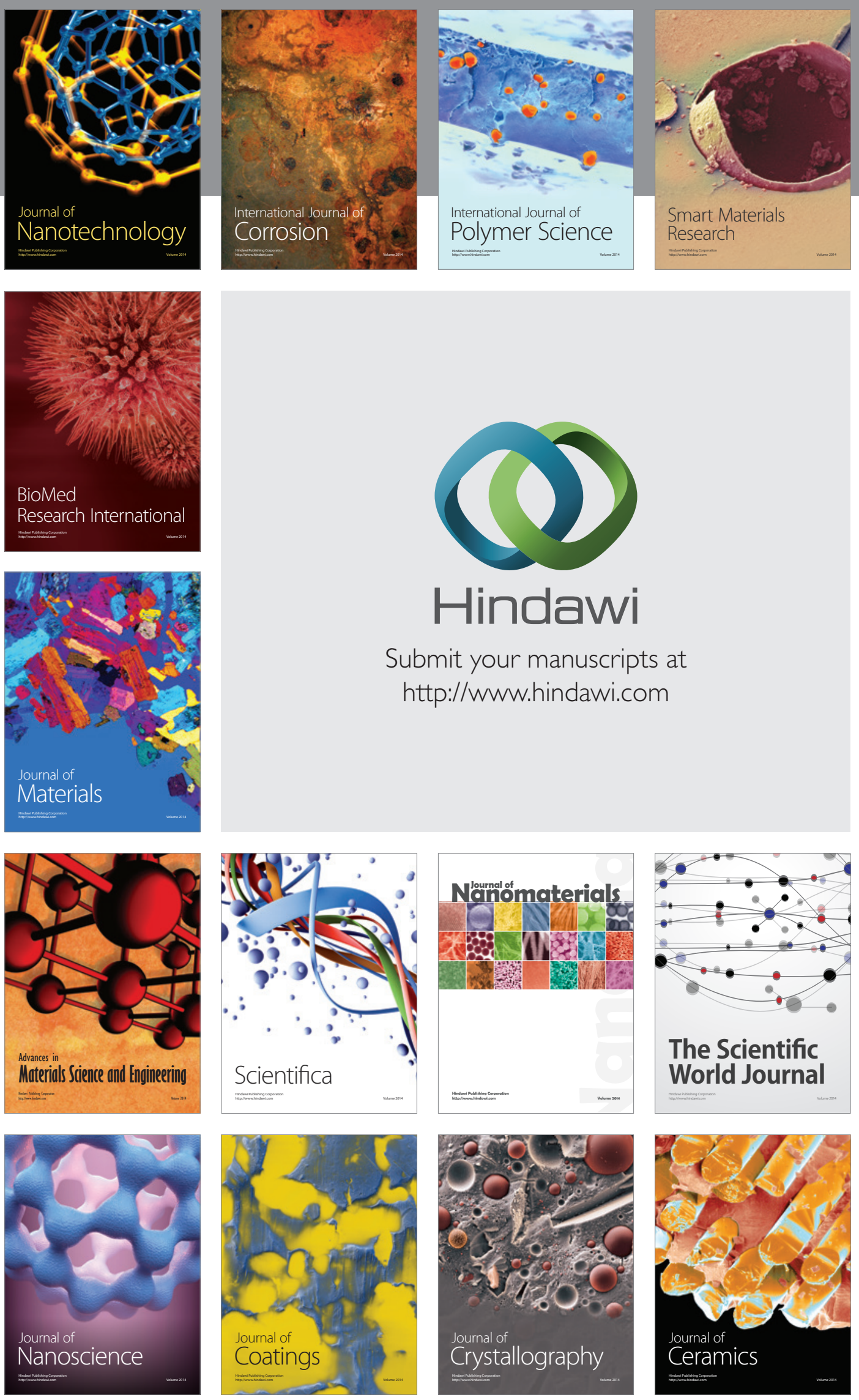

The Scientific World Journal

Submit your manuscripts at

http://www.hindawi.com

\section{World Journal}

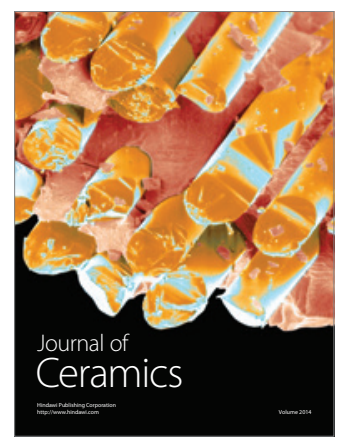

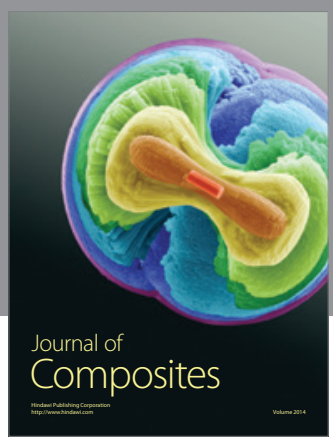
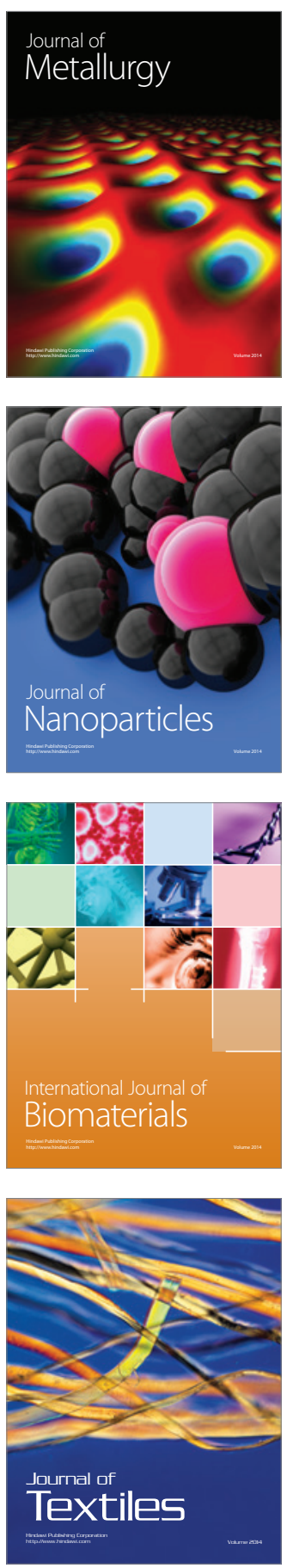